\title{
A chiral thiourea and a phosphazene for fast and stereoselective organocatalytic ring-opening-polymerization of racemic lactide.
}

Received 00th January 20xx, Accepted 00th January 20xx

DOI: $10.1039 / x 0 \times x 00000 x$

\author{
Mohamed Samir ZAKY a , Anne-Laure WIROTIUSa, Olivier COULEMBIER ${ }^{\mathrm{b}}$, Gilles GUICHARD ${ }^{c}$ and \\ Daniel TATON*a
}

Control of stereoregularity is inherent to precision polymerization chemistry for the development of functional materials. A prototypal example of this strategy is the ring-opening polymerization (ROP) of racemic lactide (rac-LA), a bio-sourced monomer. Despite significant advances in organocatalysis, stereoselective ROP of rac-LA employing chiral organocatalysts remains unexplored. Here we tackle that challenge by resorting to the Takemoto's catalyst, a chiral aminothiourea, in presence of a phosphazene base. This chiral binary organocatalytic system allows for fast, chemo- and stereoselective ROP of rac-LA at room temperature, yielding highly isotactic, semi-crystalline and metalfree polylactide, with a melting temperature as high as $187^{\circ} \mathrm{C}$.

Polylactide (PLA) is a commercially available, bio-derived, fully biodegradable and recyclable thermoplastic. ${ }^{1-2}$ PLA is a very promising substitution of petroleum-based polymers in various applications, notably in the biomedical, pharmaceutical and packaging fields. ${ }^{3-5}$ Thermo-mechanical properties of PLA strongly depend however on its microstructure, i.e. its tacticity. ${ }^{6}$ While atactic PLA is amorphous showing a glass transition $\left(T_{\mathrm{g}}\right)$ around $50{ }^{\circ} \mathrm{C}$, both heterotactic and isotactic PLAs exhibit semicrystalline properties, with a melting temperature $\left(T_{\mathrm{m}}\right)$ in the 130-180 ${ }^{\circ} \mathrm{C}$ range and improved mechanical strength. Interestingly, L-PLA and D-PLA enantiomers can co-crystallize when blended in a 1:1 molar ratio, forming a stereocomplex showing an even higher $T_{\mathrm{m}}$, i.e. up to $230^{\circ} \mathrm{C} .{ }^{7}$ Control over the stereochemistry of PLA thus plays a crucial role, as it defines its crystallinity and biodegradability, and the final usage of PLAbased materials. ${ }^{8-9}$ The stereoselective ring-opening polymerization (ROP) of racemic lactide (rac-LA) is a typical example of stereocontrolled polymer synthesis. Two distinct mechanisms can take place in that case, namely, the enantiomorphic site control (ESC) mechanism and the chainend control (CEC) mechanism. ${ }^{10-11}$ Stereoselective ROP of racLA has mainly been accomplished from organometallic complexes operating by coordination-insertion. Aluminumbased complexes featuring salen-type ligands, as originally

a. Laboratoire de Chimie des Polymères Organiques (LCPO), Université de Bordeaux, INP-ENSCBP, 16 av. Pey Berland, 33607 PESSAC cedex, France. E-mail: taton@enscbp.fr; Tel: +33(0)54000 86.

b. Center of Innovation and Research in Materials and Polymers (CIRMAP), Laboratory of Polymeric and Composite Materials, University of Mons, B-7000 Mons, Belgium.

Univ. Bordeaux, CNRS, CBMN, UMR 5248, Institut Européen de Chimie et Biologie, 2 rue Robert Escarpit, F-33607 Pessac, France.

+ Electronic Supplementary Information (ESI) available: [details of any supplementary information available should be included herel. See DOI: 10.1039/x0xx00000x reported by Spassky et $a .^{12}$ and further by many other groups, ${ }^{13-18}$ are representative examples of metal-based catalysts. While excellent stereocontrol can be achieved, there are some limitations to overcome. For instance, metal-based catalyst storage is tedious, adding to the final cost of the resulting PLA. Finally, stereoselective ROP reactions sometimes require very low reaction temperatures. Consequently, there is still a need to develop catalytic systems that could simultaneously exhibit high activity, (stereo)selectivity under mild conditions, i.e. at room temperature or above, easy synthesis and facile handling. Organocatalysts have emerged as attractive alternatives of organometallic catalysts in ROP reactions. ${ }^{6}$ This is due to the high polymerization control they provide, some of them, e.g. $\mathrm{N}$-heterocyclic carbenes (NHCs) (1, 2; Figure $\mathbf{1})^{19}$, phosphazenes $(3,4)^{20-21}$, guanidines $(5)^{22}$, thioureas $(6)^{24,30-32}$ or amino acids $(7)^{25}$ exhibiting high polymerization rates. To date, only a handful of studies of stereocontrolled ROPs of rac-LA, employing either chiral or achiral organo-based catalysts, have been reported (Figure 1). ${ }^{19-29}$ However, organocatalysts combining high stereoselectivity and catalytic activity are lacking. In this context, our group has recently reported that the commercial $(R, R)$ and $(S, S)$ enantiomers of chiral thiourea-amine Takemoto's organocatalysts can promote rather high isoselectivity of the ROP of rac-LA, yielding isotactic enriched PLA. ${ }^{24}$ Related kinetic studies have evidenced the concomitant occurrence of both CEC and ESC mechanisms. Despite excellent control, ROP reactions have shown a rather poor catalytic activity. Recently, the Waymouth group and others have established that treatment of (thio)ureas with a strong base generates (thio)imidates anions, providing unprecedented activity for the ROP of cyclic esters, overcoming some of the limitations associated with the use of (thio)ureas. ${ }^{32-34} \mathrm{We}$ envisioned that, if used in conjunction with a phosphazene organic base, Takemoto's organocatalysts could combine both high polymerization activity and stereoselectivity in a cooperative manner (Figure 1). Here we report a unique chiral binary organocatalysis system consisting of the chiral Takemoto's catalyst used in conjunction with a phosphazene base. This combination enables to achieve a remarkably high organocatalytic activity and stereoselectivity for the ROP of rac- 
LA, yielding metal-free PLAs with a melting temperature as high as $187^{\circ} \mathrm{C}$, and a probability for forming meso dyads $\left(P_{m}\right)$ of 0.96 .

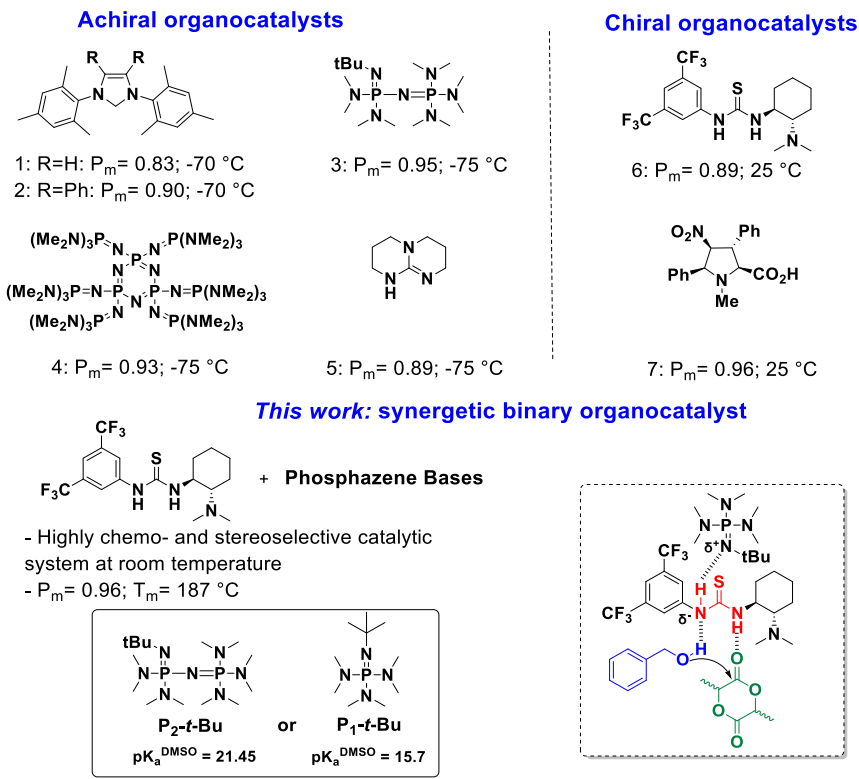

Figure 1. Organocatalysts for stereoselective ROP of rac-LA.

Organic bases such as 1-tert-butyl-2,2,4,4,4pentakis(dimethylamino)- $2 \Lambda^{5}, 4 \Lambda^{5}$-catenadi(phosphazene) ( $\mathbf{P}_{\mathbf{2}}$ $\boldsymbol{t}$-Bu) and tert-butylimino-tris(dimethylamino)phosphorane, $\mathrm{N}^{\prime}$ tert-butyl- $\mathrm{N}, \mathrm{N}, \mathrm{N}^{\prime}, \mathrm{N}^{\prime}, \mathrm{N}^{\prime \prime}, \mathrm{N}^{\prime \prime}$-hexamethylphosphorimidic triamide $\left(\mathbf{P}_{1}-\mathbf{t}-\mathbf{B u}\right)$ were paired with the Takemoto's chiral thioureabased organocatalysts (TUCS). ROP reactions were carried out by adding the phosphazene base and the TUC in this order, followed by benzyl alcohol $(\mathrm{BnOH})$ and rac-LA at room temperature, using either DCM, THF or toluene as solvent (ESI, Scheme S1). The ROP of rac-LA was first investigated in toluene using $\mathrm{P}_{2}-t-\mathrm{Bu}$ and $\mathrm{P}_{1}-t-\mathrm{Bu}$ alone, under the following conditions: $[\mathrm{rac}-\mathrm{LA}]_{0} /[\mathrm{BnOH}]_{0} /[\text { Base }]_{0}=200 / 1 / 1 . \quad \mathrm{P}_{2}-t-\mathrm{Bu}$ and $\mathrm{P}_{1}-t-\mathrm{Bu}$ achieved $90 \%$ monomer conversion in 30 and $120 \mathrm{~min}$, respectively, forming PLAs of narrow dispersities $(\theta=1.2$ and 1.3; Table 1, runs 1 and 6). These PLA materials synthesized from phosphazene bases used alone were found to be atactic (ESI, Figures S1 and S8), indicating the absence of stereocontrol at room temperature during the ROP of rac-LA. To optimize catalytic performances and gain in stereoselectivity, chiral TUCS were associated to phosphazene bases, and their ratio was increased from $1 / 1$ to $4 / 1$ rel. to the phosphazene. When using $\mathrm{P}_{2}-t$-Bu paired with both the $(R, R)$ and the $(S, S)$ TUCs, the ROP of rac-LA in toluene proceeded under homogeneous conditions at $25{ }^{\circ} \mathrm{C}$. Monomer conversions reached $90 \%$ within 4 hours (Table 1, run 5). It is worth pointing out that polymerizations carried out in THF or in DCM produced atactic PLAs, under otherwise identical conditions to those used in toluene (ESI, Table S1, runs 1-2; Figures S2 and S9).

Homodecoupled ${ }^{1} \mathrm{H} \quad$ NMR spectroscopy of the resulting compounds revealed the formation of highly isotactic-enriched PLAs, with $P_{m}$ values in the range $0.87-0.89$ (Table 1, runs 3, 4 and 5 ). Interestingly, $\mathrm{P}_{1}-t-\mathrm{Bu}$, a less hindered and weaker base with a $\mathrm{pK}_{\mathrm{a}}$ value closer to that of the TUCs $\left(\mathrm{pK}_{\mathrm{a}}=15.7\right.$ and 13.7, respectively in DMSO), ${ }^{36-37}$ led to an extremely high stereoselectivity $\left(P_{m}=0.96\right.$; Table 1, run 10; Figure 2.a). This result thus compares to values that can be achieved from some organometallic catalytic systems. ${ }^{38-39}$ Polymerization exhibited, however, a slightly lower activity, reaching $90 \%$ within 8 hours. In addition, $\mathrm{P}_{1}-\mathrm{t}$-Bu showed stereoselectivity even at 45 and 80 ${ }^{\circ} \mathrm{C}$ in toluene. As expected though, stereocontrol was found to decrease upon increasing temperature, i.e. $\mathrm{P}_{\mathrm{m}}=0.84$ and 0.75 respectively (Table S1, runs 3 and 4; ESI, Figure S4). On the other hand, increasing the ratio of TUC to the phosphazene base, from 0 to 4 , improved the stereocontrol significantly, with an evolution from an entirely amorphous and atactic PLA in presence of $\mathrm{P}_{1}$ - $t$-Bu alone, to a highly semi-crystalline PLA with a $P_{m}$ of 0.96. Use of an excess of TUC did not show any effect on monomer conversion in the concentration range examined. This observation is in contrast to previous results by Kiesewetter et al. who reported that the catalytic activity of thioureas can be compromised by side self-associations at high concentrations. ${ }^{40}$ Differential scanning calorimetry (DSC) analyses confirmed the formation of semi-crystalline PLA materials synthesized from the duo of organic catalysts consisting of the chiral TUC and the phosphazene base, with a defined melting temperature $\left(T_{\mathrm{m}}\right)$ at ca. $160-187^{\circ} \mathrm{C}$. The extent of crystallinity could be appreciably enhanced upon annealing, with a $T_{m}$ value of the PLA prepared from $\mathrm{P}_{1}-t-\mathrm{Bu} / \mathrm{TUC}(1 / 4)$ (Table 1, run 10) being increased from $187^{\circ} \mathrm{C}$ to $195^{\circ} \mathrm{C}$ after annealing (Figure 2.b).
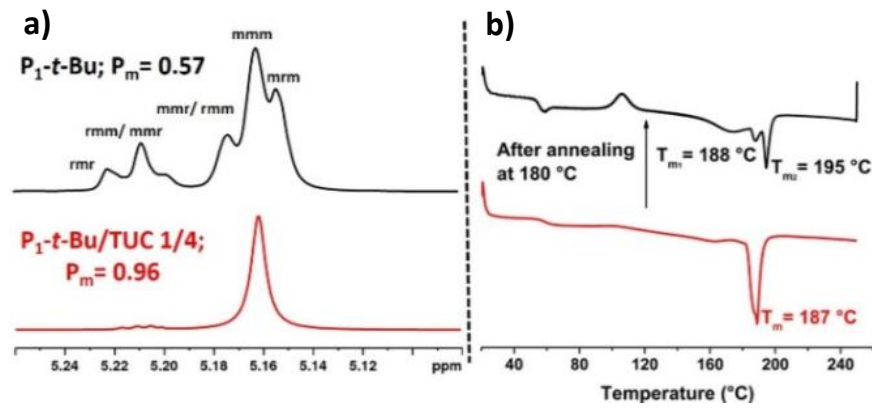

Figure 2.a. Stacked homodecoupling ${ }^{1} \mathrm{H}$ NMR spectrum of the methine region of PLA produced using $\mathrm{P}_{1}-t-\mathrm{Bu}$ (Table 1, run 6) (black curve) and $\mathrm{P}_{1}-t$-Bu/TUC (Table 1, run 10) (red curve). Figure 2.b. DSC thermograms ( $1^{\text {st }} \mathrm{scan} ; 10^{\circ} \mathrm{C} / \mathrm{min}$ ) of the initial (red curve) and annealed (black curve) PLA (Table 1, run 10).

Interactions involved between TUC, the phosphazene base and the $\mathrm{BnOH}$ alcohol initiator were probed by ${ }^{1} \mathrm{H}$ NMR spectroscopy in toluene- $d_{8}$, from equimolar amounts of each component at room temperature. The ${ }^{1} \mathrm{H}$ NMR spectra (ESI, Figure S5) showed that complete deprotonation of TUC by $\mathrm{P}_{2}-t-$ $\mathrm{Bu}$ occurred, forming the corresponding phosphazenium thioimidate $\left(\mathrm{P}_{2}-t-\mathrm{Bu} / \mathrm{TUC}\right.$ ion pair), as evidenced by the disappearance of signals due to the $\mathrm{N}-\mathrm{H}$ proton $(\delta=2.7$ and 3.9 $\mathrm{ppm}$ ) and the appearance of a new broad peak ( $\delta=5.7 \mathrm{ppm})$, which can be assigned to the protonated amine of the resulting phosphazenium. In contrast, $\mathrm{N}-\mathrm{H}$ proton of TUC only slightly shifted in presence of $\mathrm{P}_{1}-t-\mathrm{Bu}$, suggesting in this case a hydrogen-bond interaction, rather than a complete deprotonation of TUC forming a phosphazenium thioimidate (Figure 1). ${ }^{41}$ 
Table 1: ROP of rac-LA using the phosphazene/(S, S) Takemoto binary organocatalytic system. ${ }^{\mathrm{a}}$

\begin{tabular}{|c|c|c|c|c|c|c|c|c|c|}
\hline Run & Catalyst (C) & {$[\mathrm{M}]_{0} /[\mathrm{C}]_{0} /[\mathrm{I}]_{0}$} & Time (min) & Conv (\%) & $\overline{M n}_{\text {calcd }}(\mathrm{kg} / \mathrm{mol})^{c}$ & $\overline{M n}_{\text {exp }}(\mathrm{kg} / \mathrm{mol})^{d}$ & $\boldsymbol{\theta}^{c}$ & $\boldsymbol{P}_{m}{ }^{e}$ & $T_{m}\left({ }^{\circ} \mathrm{C}\right)^{f}$ \\
\hline 1 & $P_{2}-t-B u$ & $200: 1: 1$ & 30 & 92 & 26 & 17 & 1.3 & 0.72 & - \\
\hline 2 & $P_{2}-t-B u / T U C$ & $200:(1 / 1): 1$ & 240 & $\geq 99$ & 28 & 26 & 1.15 & 0.87 & 160 \\
\hline 3 & $\mathrm{P}_{2}-t-\mathrm{Bu} / \mathrm{TUC}$ & $200:(1 / 2): 1$ & 240 & $\geq 99$ & 28 & 25 & 1.05 & 0.87 & 163 \\
\hline 4 & $P_{2}-t-B u / T U C$ & $200:(1 / 3): 1$ & 240 & $\geq 99$ & 28 & 25 & 1.04 & 0.88 & 168 \\
\hline 5 & $P_{2}-t-B u / T U C$ & $200:(1 / 4): 1$ & 240 & $\geq 99$ & 28 & 29 & 1.06 & 0.89 & 167 \\
\hline 6 & $P_{1}-t-B u$ & 200:1:1 & 120 & $\geq 99$ & 28 & 23 & 1.3 & 0.57 & - \\
\hline 7 & $\mathrm{P}_{1}-t-\mathrm{Bu} / \mathrm{TUC}$ & $200:(1 / 1): 1$ & 480 & 90 & 26 & 24 & 1.05 & 0.91 & 178 \\
\hline 8 & $P_{1}-t-B u / T U C$ & $200:(1 / 2): 1$ & 480 & 92 & 26 & 23 & 1.04 & 0.93 & 185 \\
\hline 9 & $P_{1}-t-B u / T U C$ & $200:(1 / 3): 1$ & 480 & 94 & 27 & 24 & 1.03 & 0.93 & 185 \\
\hline 10 & $P_{1}-t-B u / T U C$ & $200:(1 / 4): 1$ & 480 & 89 & 25 & 23 & 1.08 & 0.96 & 187 \\
\hline
\end{tabular}

a) Polymerizations were performed in dry toluene at $25{ }^{\circ} \mathrm{C}$ with $[\mathrm{rac}-\mathrm{LA}]_{0}=0.08 \mathrm{M}$. b) Monomer conversion determined by ${ }^{1} \mathrm{H} \mathrm{NMR} \mathrm{in} \mathrm{CDCl}_{3}$ using integrals of the characteristic signals. $\left.{ }^{c}\right) \mathrm{M}_{\mathrm{n} \text {, calc }}=\mathrm{M}_{\mathrm{LA}}\left(144.13 \mathrm{~g} \cdot \mathrm{mol}^{-1}\right) \times\left([\mathrm{LA}]_{0} /[\mathrm{I}]_{0}\right) \times$ conversion $+\mathrm{M}_{\mathrm{BnOH}}\left(108.14 \mathrm{~g} \cdot \mathrm{mol}^{-1}\right)$. $\left.{ }^{\mathrm{d}}\right)$ Determined by SEC in THF relative to PS standards using a correcting factor of $0.58^{35}$. ${ }^{e}$ Determined by homonuclear decoupled ${ }^{1} \mathrm{H}$ NMR. ${ }^{\mathrm{f})}$ Determined by DSC.

Adding $\mathrm{BnOH}$ onto the $\mathrm{P}_{2}-t-\mathrm{Bu} / \mathrm{TUC}$ ion yielded the corresponding phosphazenium alkoxide $\left(\mathrm{BnO}^{-}\right)$ion pair (red line, Figure 3 ). This was confirmed by a reduced deshielding effect of the methylene protons (A, Figure 3 ) in the $\mathrm{BnOH} / \mathrm{TUC} / \mathrm{P}_{2}-t-\mathrm{Bu}(1 / 1 / 1)$ mixture $(\delta=4.63 \mathrm{ppm})$, relatively to the $\mathrm{BnOH} / \mathrm{P}_{2}-t-\mathrm{Bu}(1 / 1)$ mixture $(\delta=4.89 \mathrm{ppm}) .{ }^{42}$ This unexpected downfield shift of benzylic protons might be explained by specific interactions developing between the alkoxide moiety and the phosphazenium cation (see Scheme S2 in ESI). A weaker deshielding effect of methylene protons of $\mathrm{BnOH}$ was noted in the case of the $\mathrm{BnOH} / \mathrm{TUC} / \mathrm{P}_{1}-t$ - $\mathrm{Bu}(1 / 1 / 1)$ mixture, in comparison to free $\mathrm{BnOH}(\delta=4.43$ vs. $4.26 \mathrm{ppm}$, purple line, Figure 3 ). In other words, $\mathrm{P}_{1}$-t-Bu would favor stereocontrol via an associated mechanism involving hydrogenbonding, as illustrated in Figure 3 (see also Figure 1). In contrast, the deprotonated form of TUC would operate in presence of the stronger phosphazene base, $\mathrm{P}_{2}-t-\mathrm{Bu}$ (higher $\mathrm{pK}_{\mathrm{a}}$ value than $\mathrm{P}_{1}-t$ $\mathrm{Bu})$. These results do correlate with a lower reactivity observed with $\mathrm{P}_{1}-t-\mathrm{Bu} / \mathrm{TUC}$.

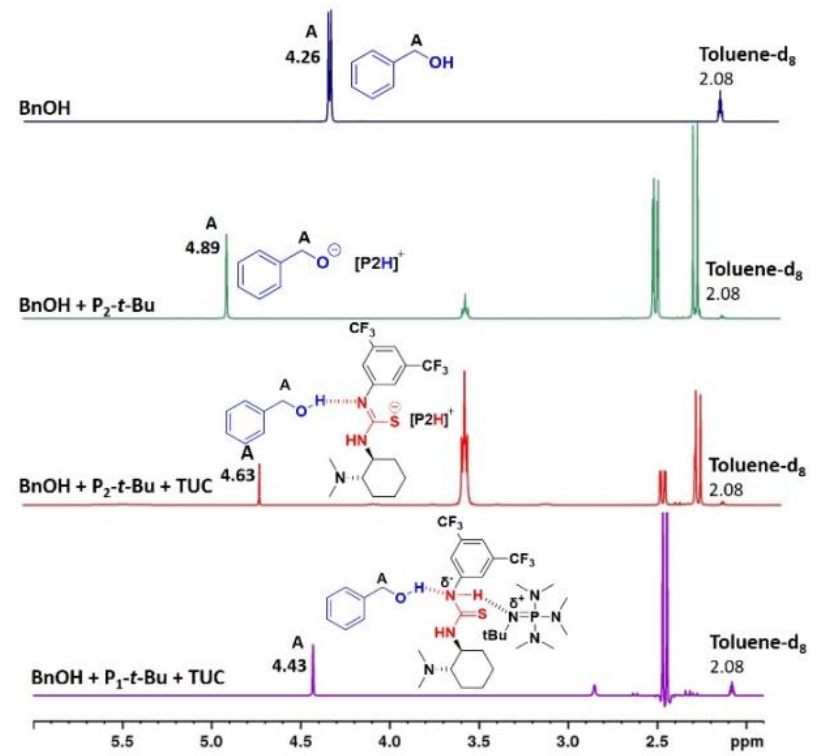

Figure 3. Stacked ${ }^{1} \mathrm{H}-\mathrm{NMR}$ experiments from equimolar amounts of $\mathrm{BnOH}, \mathrm{BnOH} / \mathrm{P}_{2}-t-\mathrm{Bu}, \mathrm{BnOH} / \mathrm{P}_{2}-t-\mathrm{Bu} / \mathrm{TUC}$ and $\mathrm{BnOH} / \mathrm{P}_{1}-t-\mathrm{Bu} / \mathrm{TUC}$ performed in dry toluene- $d_{8}$ at room temperatue, (the signal around $2.5 \mathrm{ppm}$ is due to methyl protons of the phosphazene base).
Kinetic studies confirmed the controlled nature of the ROP of rac-LA by $\mathrm{P}_{2}-t-\mathrm{Bu} / T U C$. Polymer number average molar masses $\left(M_{n}\right)$ were indeed found to increase linearly with the monomer conversions, and dispersities remained very low, consistently with a controlled ROP process and high chain-end fidelity (Figures 4.a and ESI, S6). Moreover, no evidence of transesterification was noted in the resulting MALDI-ToF mass spectrum, i.e. no detection of a molar mass loss of $72 \mathrm{~g} \mathrm{~mol}^{-1}$ was observed, highlighting the selectivity of the chiral binary organocatalytic system for the ROP of rac-LA (Figure 4.b). The isotopic single distribution of peaks was consistent with the formation of an $\alpha$-benzyloxy, $\omega$-hydroxy PLA (cationized with sodium), with a peak-to-peak mass increment of $144 \mathrm{~g} \cdot \mathrm{mol}^{-1}$ corresponding to the molar mass of a LA monomer unit.

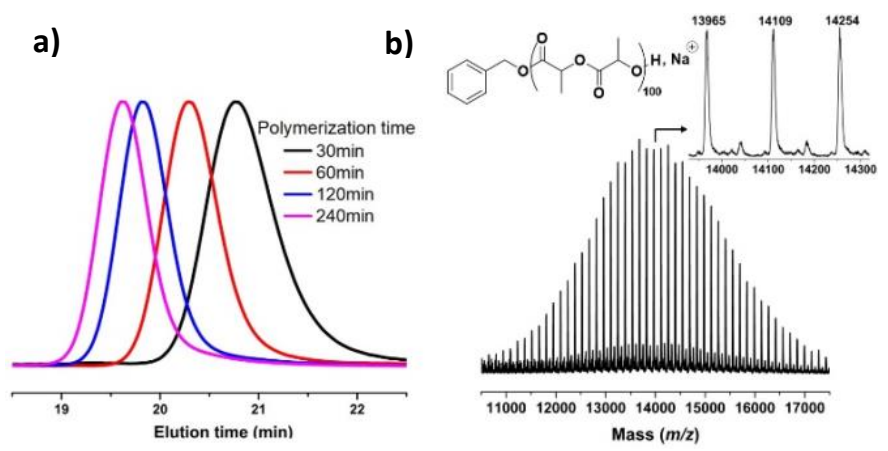

Figure 4. (a) SEC traces of PLA crude sample at different conversions (Table 1, run 5) and (b) Experimental MALDI ToF MS of PLA using $P_{2}-t$ Bu/TUC (1/4).

Further experiments involving $\mathrm{P}_{1}-t-\mathrm{Bu} /(S, S)$ TUC allowed assessing the stereocontrol of this organocatalytic ROP process. The determination of the propagation rate constant, denoted as $k_{o b s}$, indeed enables to estimate any preference of the catalyst for a given monomer ( $D$-LA vs. L-LA). Monitoring the ROP of rac-LA revealed a first-order kinetic with two distinct slopes $\left(\mathrm{kobs}^{-1}=0.015, \mathrm{kobs}^{-1}=0.0065 ; \mathrm{ESI}\right.$, Figure S7). A decrease in rate could be noted after 200 minutes. This deceleration is ascribed to the preferential consumption of a given enantiomer by a given TUC. These results support that the chirality of the catalyst defines the stereochemistry of the subsequent monomer insertion during chain propagation, 
suggesting that the enantiomorphic site control mechanism (ESC) is dominant during the ROP of rac-LA catalyzed by the combined use of the chiral TUC and the phosphazene base.

In summary, organocatalyst design, associating a chiral commercial aminothiourea and an organic phosphazene base, shows a synergetic and highly effective effect to carry out the ROP of rac-LA, with both a high catalytic activity $(90 \%$ conversion within $3-8 \mathrm{~h})$ and a very high stereoselectivity $\left(\mathrm{P}_{\mathrm{m}}=\right.$ $\left.0.96, \mathrm{~T}_{\mathrm{m}}=187^{\circ} \mathrm{C}\right)$. A weaker phosphazene base $\left(\mathrm{P}_{1}-\mathrm{t}-\mathrm{Bu}\right)$ fosters stereocontrol, likely via an associated mechanism involving hydrogen-bonding, whereas the stronger phosphazene base, $\mathrm{P}_{2}-t-\mathrm{Bu}$, provides faster polymerization but lesser stereocontrol, via a phosphazenium thioimidate ion pair generated in situ. Stereocontrol is achieved by the ESC mechanism, providing metal-free and highly crystalline PLA materials in the $25-80{ }^{\circ} \mathrm{C}$ temperature range. This binary organocatalytic system combining a chiral aminothiourea and a strong organic base opens up new avenues for the development of stereocontrolled ROP in general.

\section{Acknowledgments}

The authors are grateful to CNRS, the French Ministry of Education and Research and to the Agence Nationale de la Recherche (ANR) HCO_for_LLAC (grant \#18-CE07-0018-02).

\section{Notes and references}

1. O. Dechy-Cabaret, B. Martin-Vaca, D. Bourissou, Chem. Rev., 2004, 104, 6147.

2. J. M. Raquez, Y. Habibi, M. Murariu, P. Dubois, Prog. Polym. Sci., 2013, 38, 1504.

3. C. Li, T. Jiang, J. Wang, H. Wu, S. Guo, X. Zhang, J. Li, J. Shen, R. Chen, Y. Xiong, ACS Appl. Mater. Interfaces, 2017, 9, 25818.

4. J. Wang, Y. Liu, Y. Ma, C. Sun, W. Tao, Y. Wang, X. Yang, J. Wang, Adv. Funct. Mater., 2016, 26, 7516.

5. L. Tang, R. Tong, V. J. Coyle, Q. Yin, H. Pondenis, L. B. Borst, J. Cheng, T. M. Fan, ACS Nano., 2015, 9, 5072.

6. M. Fèvre, J. Vignolle, Y. Gnanou, D. Taton, Organocatalyzed Ring-Opening Polymerizations; Elsevier B.V., 2012; Vol. 4.

7. K. Fukushima, Y. Kimura, Polym. Int., 2006, 55, 626.

8. H. Tsuji, Macromol. Biosci., 2005, 5, 569.

9. M. Wisniewski, A. Le Borgne, N. Spassky, Macromol. Chem. Phys., 1997, 198, 1227.

10. T. M. Ovitt, G. W. Coates, J. Am. Chem. Soc., 2002, 124, 1316

11. P. Marin, M. J.-L. Tschan, F. Isnard, C. Robert, P. Haquette, X. Trivelli, L-M. Chamoreau, V. Gurineau, I. del Rosal, L. Maron, V. Venditto and C. M. Thomas, Angew. Chem. Int. Ed., 2019, 58, $12585-12589$.

12. N. Spassky, M. Wisniewski, C. Pluta, A. Le, Macromol. Chem. Phys., 1996, 2637, 2627.

13. C. P. Radano, G. L. Baker, M. R. Smith, J. Am. Chem. Soc., 2000, 122, 1552.

14. N. Nomura, R. Ishii, Y. Yamamoto, T. Kondo, Chem.Eur. J., 2007, 13, 4433

15. Z. Zhong, P. J. Dijkstra, J. Feijen, Angew. Chem. Int. Ed., 2002, 41,4510 .
16. K. Majerska, A. Duda, J. Am. Chem. Soc., 2004, 126, 1026.

17. W. Luo, T. Shi, S. Liu, W. Zuo, Z. Li, Organometallics, 2017, 36,1736

18. M. J. Stanford, A. P. Dove, Chem. Soc. Rev., 2010, 39, 486.

19. A. P. Dove, H. Li, R. C. Pratt, B. G. G. Lohmeijer, D. A. Culkin, R. M. Waymouth, J. L. Hedrick, Chem. Commun., 2006, 2881.

20. L. Zhang, F. Nederberg, J. M. Messman, R. C. Pratt, J. L. Hedrick, C. G. Wade, J. Am. Chem. Soc., 2007, 129, 12610.

21. S. Liu, H. Li, N. Zhao, Z. Li, ACS Macro Lett., 2018, 7, 624.

22. S. Moins, S. Hoyas, V. Lemaur, B. Orhan, K. Delle Chiaie, R. Lazzaroni, D. Taton, A. P. Dove and O. Coulembier, Catalysts, 2020, 10, 620.

23. J. Y. C. Lim, N. Yuntawattana, P. D. Beer, C. K. Williams, Angew. Chemie - Int. Ed. 2019, 58, 6007.

24. B. Orhan, M. J.-L. Tschan, A.-L. Wirotius, A. P. Dove, O. Coulembier, D. Taton, ACS Macro Lett., 2018, 1413.

25. A. Sanchez-Sanchez, I. Rivilla, M. Agirre, A. Basterretxea, A. Etxeberria, A. Veloso, H. Sardon, D. Mecerreyes, F. P. Cossío, J. Am. Chem. Soc., 2017, 139, 4805.

26. G. M. Miyake, E. Y. X. Chen, Macromolecules, 2011, 44, 4116.

27. K. Makiguchi, T. Yamanaka, T. Kakuchi, M. Terada, T. Satoh, Chem. Commun., 2014, 50, 2883.

28. J. B. Zhu, E. Y. X. Chen, J. Am. Chem. Soc., 2015, 137, 12506.

29. C. Lv, L. Zhou, R. Yuan, Q. Mahmood, G. Xu and Q. Wang, New J. Chem., 2020, 44, 1648-1655.

30. N. U. Dharmaratne, J. U. Pothupitiya and M. K. Kiesewetter, Org. Biomol. Chem., 2019, 17, 3305-3313.

31. R. S. Hewawasam, U. L. D. Inush Kalana, N. U. Dharmaratne, T. J. Wright, T. J. Bannin, E. T. Kiesewetter, and M. K. Kiesewetter, Macromolecules, 2019, 52, 9232-9237.

32. B. Lin, R. M. Waymouth, J. Am. Chem. Soc., 2017, 139, 1645.

33. X. Zhang, G. O. Jones, J. L. Hedrick, R. M. Waymouth, Nat. Chem., 2016, 8, 1047-1053.

34. I. Jain and P. Malik, European Polymer Journal, 2020, 133, 109791.

35. M. Save, M. Schappacher, Macromol. Chem. Phys., 2002, 203, 889-899.

36. G. Jakab, C. Tancon, Z. Zhang, K. M. Lippert, P. R. Schreiner, Org. Lett., 2012, 14, 1724-1727.

37. I. Kaljurand, A. Kutt, L. Soovali, T. Rodima, Maemets, V. Maemets, I. Leito, I. A. Koppel, J. Org. Chem., 2005, 70, 1019.

38. A. J. Chmura, M. G. Davidson, C. J. Frankis, M. D. Jones and M. D. Lunn, Chem. Commun., 2008, 1293.

39. C.-X. Cai, A. Amgoune, C. W. Lehmann and J.-F. Carpentier, Chem. Commun., 2004, 330.

40. O. I. Kazakov, P. P. Datta, M. Isajani, E. T. Kiesewetter, and M. K. Kiesewetter, Macromolecules, 2014, 47, 7463-7468.

41. X. Wang and N. Hadjichristidis, Macromolecules, 2020, 53, 223-232.

42. R. Yuan, G. Xu, C. Lv, L. Zhou, R. Yang, Q. Wang, Materials Today Communications, 2020, 22, 100747. 